\title{
Daily stock movements through the lens of Event and News: Evidence from the Pakistan Stock Exchange
}

\section{Shahid Raza ${ }^{1 *}$ Sun Bai Qing ${ }^{2}$ and Pwint Kay Khine ${ }^{3}$}

\author{
1* School of Management, Harbin Institute of Technology, China; razashahid@,hit.edu.cn \\ ${ }^{2}$ School of Management, Harbin Institute of Technology, China; baiqingsun@hit.edu.cn \\ ${ }^{3}$ School of Management, Harbin Institute of Technology, China; pkaykhine@gmail.com
}

\begin{abstract}
This study will investigate different signals and events/news that determined the stock market's movements. As we know, many factors affect the stock market on a daily, weekly, and monthly basis, e.g., rate of interest, exchange rate, and oil prices, etc. Our research will investigate the impact of daily events/news in the KSE-100 index due to several policies announced and events/news in the country because the daily movements in the stock market can be determined only by different signals and events/news. Time series data is collected daily for particular reasons from "The News" (Daily Newspaper, Sunday edition) from 2010 to 2019. The results of this study show that political and global news affects the stock market index ferociously. For investors, the investment in blue chips is not less than a safe haven. When day-to-day transactions are concerned, there is always a higher panic attack than the herd behaviour in the stock exchange. Investors tend to make prompt responses to negative rather than positive news, which makes them risk averters. Our finding also confirmed that the ARCH/GARCH model is better than the simple OLS method concerning stock market upheaval.
\end{abstract}

Keywords: Stock Market, Financial Markets, News Model, KSE 100 Index, ARCH/GARCH, OLS 


\section{Introduction}

It is difficult to forecast market volatility based on economic and financial data. Prior studies on stock markets merged macro- and macroeconomic analysis with stock data on a weekly, monthly, or annual basis; however, these studies ignore the influence of news on market fluctuations. When stock prices are fluctuating, many elements can be observed. The following elements are integrating with news/events and are particular events that can lead to speculation. Thus, we investigated market volatility by news factors (e.g., political, economic, and financial). Investing in stocks in a developing country can result in better value by making investors well-informed regarding the most effective news factors on the stock market. In our analysis, we want to highlight how much a news story can affect the market.

The stock exchange provided a platform for an individual to purchase and sell shares, which is compulsory in the market economy of one country. People receive in return ownership when they invest capital in the stock market. According to Singh [1], the stock exchange is indeed the face of the money market, establishing a place for traders to fulfill their financial obligations effectively. As the upheaval in the stock market may occur at any time, it is challenging to forecast ups and downs through economic and financial. Because of its volatile and unpredictable behavior, the stock market is often named "a confused and troublesome market." Research has conducted numerous studies by explaining that the stock market performs a vital role in a nation's growth [2]. Fama [3] used three different types of tests: weak form, semi-solid form, and strong form. Weak type measures, according to him, describe the knowledge collection that is only accessible for time series. Furthermore, the semi-strong type is concerned with whether rates respond effectively to other data that is generally accessible to the public, such as stock splits, while the strong form is concerned with whether information related to market forming is measured.

Researches have been carried to examine the associations between the country's financial market and other elements because of its significance. According to Fama [4], the stock market is determined by the type of money supply. Changes in exchange rates have a reasonably immediate and obvious effect. While the inflation effect exceeds the aggregate projected wage and income impact, monetary inflation lowers short-term interest rates. To understand the stock market dynamics, one should know the fundamental factors of the stock market properly. Extensive studies already established important macroeconomic and structural factors that could shift the financial markets in this way. Although the number of previous studies seems to have increased 
over time, the empirical research remains small. It needs a precise analysis of the analytical models to construct the stock market determinants as practiced by the financial system. As a result, it is not unusual to observe the determinants of stock market performance that try to explain these socalled factors exerting economic theory.

In every developing country, the stock exchange is vital in the development of one country. People bet on a stock exchange. Kemboi \& Tarus [5] investigated macroeconomic factors that determine a nation's stock market performance. A recent analysis examined the impact of macroeconomics variables on stock market growth [6]. However, trading in the stock exchange is not ideal for everyone because of its unpredictable nature. Individuals may lose all their investments, but that is rare.

When stock prices move up and down, many elements can be observed. These elements are incorporating with news/events and are particular catastrophes that can cause speculations. Elements that initiated turmoil in the stock market are political and social tension, financial news, global news, news related to institutions, etc. As per Fama [7], research analysts frequently use two main approaches to predict stock prices: "chartist" or "scientific" approaches and the concept of fundamental or intrinsic value analysis.

The basic principle for chartist or technological hypotheses, he said, is that experience continues to repeat itself. As a result, only one way to estimate the stock price using technical theory is to become acquainted with historical price trends to spot prolonged conditions. The escalation of these elements makes a bullish or bearish atmosphere on stock data among purchasers and merchants. When there are more sellers in the stock exchange, the stock costs tend to decline. Contrary to this, when there are more purchasers, stock costs will go up.

In the recent era, the top reputed, established traders in financial markets increasingly use the "sentiment" indicators as their new Information source resulting from news wire articles. The easy access to such low- 'meta information'- "news about the news"- provides a competitive advantage to many of its operators, like highly algorithmic hedge funds and frequency traders.

There is a large number of researches has been conducted by different researchers [8-11] in their research to check the effects on stock prices by the information from traditional media sources. The economic, political, and social reasons also determine the effectiveness of Pakistan's stock markets. 


\subsection{What is Good News/Bad News}

- People usually sell their stocks because of Negative News. The economic instability and political uncertainty, ups and downs in corporate governance, financial crises in the country, and unfortunate incidences to selling pressure and the prices decrease almost every stock or the majority of their stocks.

- People usually buy stocks when there is a piece of positive news occurs. The positive economic and financial position indicators, profit-earning reports, growth in corporate acquisitions, and political stability all cause the buying pressure and cause an increase in stock prices in the market.

For example, an incorrect Twitter feed in 2013 about an explosion in the White House explosion triggered a crash in U.S. markets. Most of the expert traders trying to forecast news cycles by spending most of their time just because they can buy or sell stocks in the market before the actual numbers were released. In this practice, they use different information sources for this.

There is an immense growth in the Pakistani stock market in the last ten years. It has gained momentum in the past ten years. In May 2017, the KSE-100 index reached the maximum historical value of 52876.46. In June 1990, it was the historic minimum value of 538.89. At present, it is one of the global emerging stock markets, and stock returns are relatively high.

Although previous studies on stock markets were merging macro- and macro-economic analysis with weekly, monthly or annual stock data, these studies overlook the influence of news on stock market fluctuations. We, therefore, analyzed the unpredictability in stock markets by news factors (i.e., political, economic and financial, etc.).

This study attempts to explain the daily fluctuations in the KSE-100 Index by local and international news and the announcement of new policies. In this study, news that is observed includes local political information such as the arrest of former Prime Minister and former President on corruption charges, financial news such as the hike of exchange rates or interest rate. This news may dull the stock market. Information of rising oil prices or News about a strained relationship between China and the U.S. may remarkably affect the stock exchange. Analyzing stock exchanges' volatile and fragile nature in developing countries from the news is crucial since news impact may generate overall disturbance in the stock exchange. 


\subsection{Background of Stock Market of Pakistan}

Stock markets offer convenience to an individual to purchase or offer stocks. Pakistan's three major stock markets were located in Karachi, Lahore, Islamabad, KSE, LSE, and ISE. Since 1997, all stock markets in Pakistan are monitored by a specific institution entitled "Security and Trade Commission Program (SECP)." In January 2016, these three stocks were combined as PSX (Pakistan Stock Exchange).

Karachi Stock Exchange (KSE) is an utmost changeable market among three stock markets dealing with high shares and exchange rates. KSE is started in 1949 with a total of 103 individuals and organizations. In 1971, the number of organizations had increased from 13 to 318 because of the development of profitable ventures. When East Pakistan separated and emerged as Bangladesh, 60 organizations from East Pakistan (Bangladesh) had de-registered. In 1973-74, the Pakistani government started nationalization of private industries.

There are two securities: KSE-30 and KSE-100. In May 2017, the closing of the KSE-100 index was 52876.46, which is an all-time high in the history of KSE. The stock market spills because of the political situation; for instance, Karachi stock trading was disturbed for more than a year since former Prime Minister Benazir Bhutto was assassinated. In 2019, Pakistani stock also suffered when spreading rumours such as Pakistan had been 'blacklisted.' From these pieces of evidence, we can understand the fragile nature of the Pakistani stock exchange itself and the forcible influences of news on it. Henceforth, our study aims to highlight and scrutinize this coercive influence of information on daily fluctuations of the Pakistani stock exchange. Based on observations, we will suggest the valuable insight of most influential factors which bring positive or negative effect to the stock market to investors in developing countries.

\subsection{Statement of the Problem}

This study will investigate different signals and events/news that determined the stock market's movements. As we know, many factors affect the stock market on a daily, weekly, and monthly basis, e.g., rate of interest, exchange rate, and oil prices, etc. Our research will investigate the impact of daily events/news in the KSE-100 index due to several policies announced and events/news in the country because the daily movements in the stock market can be determined only by different signals and events/news. Various researches have examined a range of macroeconomic factors that affect the stock market. However, no conclusion has been established about which determinant influences in stock markets, yet no one has used the News method to 
forecast stock market movements. Our study uses ARCH/GARCH approaches because the simple OLS method is not explained well when it comes to stock market upheaval.

\subsection{Research questions}

This study will investigate the following research questions essential for this study.

a. Does stock market performance is affected by the news/events that occur in the country?

b. How much is this change/effect is associated with the news/events?

c. Does the stock market is affected more by positive news/events or negative?

d. What is the impact of different news on movements of stock market?

\subsection{Contribution to the literature}

The News factor has often been neglected by most studies when examining the movements of the stock market. The present study has contributed to filling this gap in current literature. The fragile nature of stock markets in developing countries is mainly affected by breaking news. This study, which we conducted in its original form, would be a valuable input for future studies of the financial markets.

It is difficult to forecast market volatility based on economic and financial data. Prior studies on stock markets merged macro- and macroeconomic analysis with stock data on a weekly, monthly, or annual basis; however, these studies ignore the influence of news on market fluctuations. When stock prices are fluctuating, many elements can be observed. The following factors are integrating with news/events and are particular events that can lead to speculation. Thus, we investigated market volatility by news factors (e.g., political, economic, and financial).

\section{Literature review}

The volatility of stocks makes it difficult to predict their future movements. Almost all researchers examining the stock market agree that "it's a random walk."[12]. Many researchers [13-16] used numerous factors to measure upheaval of the stock exchange and prices. A major crash in the Pakistani stock market happened in 2005 (for the first time), 2006, and 2008-2009.

We have seen changes in the focus of the study of stock markets lately. It becomes more focused on news data. [17] focused on microblogging data and the stock market. Using Granger causality analyses and time-delay detrended cross-correlation analysis (DCCA), he demonstrated a strongly correlated new metric (Sina Weibo Index) with stock market volatility. 
Similarly, internet news and queries have the predictive potential for indexes [18], while sensitive knowledge only has adequate consistency with fluctuations. It indicated the positive correlation of internet news and investigations on stock performance indicators, whereas the negative correlation of private information with turnover and volatility.

Hussain \& Omrane [19] employed high-frequency 5-min data to examine the impact of U.S. macroeconomic news announcements on the Canadian benchmark stock return and uncertainty. News developments have a highly significant effect on stock price return and uncertainty, according to the researchers. Furthermore, just after the 2008 U.S. crisis, there were significantly more U.S. news stories that significantly impacted Canadian stock returns, with reasonably strong results.

The news announcements have evolved into an essential source of knowledge for ordinary people. The research used in the analysis [20] forecast equity returns in the Taiwan stock market using the news model. Although the out-of-sample output is only slightly increased, their statistical review found that the news variables offer valuable knowledge in forecasting Taiwan stock market returns. Market sentiment also has an inverted impact on stock market returns, according to research. Whenever the stock market is growing, rather than sluggish, the forecast is more reliable.

Volatilities in the Pakistani stock market occurred due to unrest in political and rule of law situations. The first two shockwaves in stock markets were because of unstable administration and financial speculation. KSE can boost through escalating political or democratic conditions [21]. Erdogan et al [22] examined the impact of uncertainty spillover from foreign exchange markets to Islamic finance. The study found that abnormal returns from the Islamic stock market have a favourable effect on Turkey's foreign exchange market and that there is at least one type of volatility spillover among exchange rates and the Islamic equity markets at specific times.

The risk spillover impact by different sectors in China's stock market shifts over Sino-US trade conflict cycles was researched [23]. They found that insufficient stock market consistency arises when certain measured stocks in China's stock market fluctuate erratically or experience targeted shocks, causing the trading relationship between China and the United States to become unpredictable, resulting in increased trade tension. Subsequently, the study categorized the fluctuation of important international stock indexes, the stock market network structure, the domestic macroeconomic indications, and the fluctuation of commodity prices in the global market as four significant indicators of abnormal movements in China's stock market. Su [24] used a 
frequency approach to analyze the dynamics and determinants of abnormal return effects in G7 financial markets. Volatility spillovers all over G7 financial markets are considered to be significantly responsive to the crisis. Low-frequency elements are the primary sources of volatility spillovers, while high-frequency elements are vulnerable to market event shocks. Contributing causes include varying impacts on short-, mid-and long-term volatility. The effect dynamics on volatility spillovers, on the other hand, really aren't static.

Another study by Dai et al. [25] used monthly volatility to predict stock markets in the U.S., Japan, Germany, France, and the U.K. Their results showed very significant Granger causality from stock market implied volatility to stock volatility. It also proved the more substantial impact of stock market implied volatility than the oil price volatility for stock volatility.

Researchers Hussain et al. [26] found that the impact of adverse shocks is considerably more significant than positive shocks by using the GARCH model. Tule et al. [27] examined stock returns and foreign exchange by the model of multivariate GARCH. They determined that there is a solid one-way effect of shocks on stocks and the foreign exchange market. Similarly, Shen [28] found that surprises in the U.S. market upsurged risk in the markets in Asia. Moreover, there is a significant impact of declining prices in Asia on risk in the U.S. market.

Since the economic activity of one country can be measured by the stock market, many types of research have linked macroeconomic and the stock market. Many researchers [14, 29] concluded the significant impact of macroeconomic factors (e.g., investment spending, expenditures, and GDP) on the stock exchange. Stock prices and industrial production have a positive relationship [30].

Saeedian et al. [31] ncluded forty stock exchange indices worldwide to find the economies with the largest GDP. Using a dendrogram of the cross-correlation matrix, they demonstrated the level of mutual involvement among the markets and the share of each economy in the worldwide network. They also show that the global capital market is divided into three groups, like stock markets nearby.

Zhang et al. [32] studied the effect of the stock market on household financial income and consumption. They discovered that households with volatile investments suffered a significant amount of money and that financial knowledge and investing experience can not reduce costs. Because of use, households with diverse risk habits and financial literacy prefer smoother consumption choices after the shock in fundamental ways. 
Studies witnessed dissimilarities of macro-and micro-economic factor's effects on stock markets. Javaid [33] observed the positive impact of market indices (dividend, earnings, and KIBOR) on stock market motions. Nazir et al. [21] also determined that corporate dividends can measure changes in stock prices.

Furthermore, the study by Nisa \& Nishat [34] concluded that previous stock costs, the size of the organization, earlier profit per share are important influences to predict stock market movements. While determining the changes in stock markets, researchers [15, 35] proved that inflation is negatively associated with stock prices. Exceptionally, Aurangzeb [36] evidenced that inflation in South Asia had no significant relation to stock market turmoil. However, Sohail \& Hussain [37] proved the positive association between stock market prices and industrial activities. Studies [30, 38] reported that stock returns and CPI are negatively associated. Additionally, renowned Fama and French [39] reported the prominent association between GNP and stock prices.

The exchange rate, except inflation, is also a significant variable to predict changes in the stock exchange. The foreign exchange rate is necessary to remain stable to ensure progress in the stock exchange. Exchange rate volatility will generate risks in the investment.

Accordingly, researchers more often inspect the changes in stock markets based on exchange rates, yet findings are varied as follows:

Table 1

Literature Findings

\begin{tabular}{l|l}
\hline Authors & \multicolumn{1}{c}{ Findings on exchange rate and stock market } \\
\hline $\begin{array}{l}\text { Muhammad \& Rasheed } \\
(2002)\end{array}$ & No significant association in short run \\
\hline $\begin{array}{l}\text { Farooq, Keung, \& Kazmi } \\
\text { (2004) }\end{array}$ & $\begin{array}{l}\text { KSE index as well as services sector index are positively related to } \\
\text { exchange rates }\end{array}$ \\
\hline Qayyum \& Kemal (2006) & No association on the long run \\
\hline Nazir, Nawaz, \& Gilani & Negative relationship \\
(2010) & \\
\hline Zia \& Rahman (2011) & No association \\
\hline
\end{tabular}




\begin{tabular}{l|l}
\hline Dr. Aurangzeb (2012) & Positive relationship \\
\hline $\begin{array}{l}\text { Mahapatra \& Bhaduri } \\
\text { (2018) }\end{array}$ & Instabilities of exchange rates caused robust effect on stock market ${ }^{1}$ \\
\hline
\end{tabular}

Exchange rates also have a significant influence on the services sector index except for the relationships mentioned above. Interest rates, along with profits of financial institutions, also impact changes in the stock market. When the central bank of Pakistan announced interest rates, the ups and downs in the stock exchange happened before and after the announcement. Many studies [16, 35, 40, 41] showed that interest rates are negatively associated with the stock market. Crude oil is a driving force for countries' interdependency. The study by Wu et al. [42] proved that crude oil significantly impacts the co-movements in international stock markets in the medium and long term. As there are differences of lower co-movement and higher co-movement of crude oil for oil-importing countries and oil-exporting countries, the co-movement is affected by other factors.

Researchers $[19,43]$ found the influence of market prices(gold and oil) on stock and exchange prices. It implies that variations of gold and oil prices, in other words, the news related to price changes, have influenced the stock exchange. Many researchers [26, 40, 41, 44] examined the effect of money supply concerning the stock exchange, then concluded the negative association. Lin \& $\mathrm{Su}$ [45] used OVX as a reliable indicator of oil market volatility and used the quantile-onquantile method to find asymmetric and heterogeneous correlations. Asymmetry was found in the analysis, with overall negative correlations between OVX shifts and Islamic stock returns. It also indicated that while oil market volatility is at greater percentiles, the consequences would be more prominent. According to this, oil-importing countries are more vulnerable than oil-exporting countries, and Islamic countries are much more susceptible than non-Islamic countries.

Cheema \& Scrimgeour [46] have investigated the connection between oil prices and Chinese stock market abnormalities. They argued that stock market irregularities are more significant as oil prices rise due to increased demand for the resource since returns associated with anomalies indicate market manipulation. A study done by Ferreiro [47] showed losses due to the decrease in oil price

\footnotetext{
${ }^{1}$ This table has included the major contributions of recent research in the Pakistan stock exchange and their results.
} 
in U.S. dollars and, on the contrary, gains for oil prices in euros highlighted the impact of exchange rate on global markets.

Cevik et al. [48] investigated the impact of crude oil prices and stock market returns in Turkey, keeping uncertainty spillovers into consideration. Their statistical findings indicated that Brent crude oil prices substantially impacted stock market returns in Turkey. They are further shown in 1993 and 2008-09 that crude oil prices significantly impacted stock market returns.

Using the corresponding volatility spillover indices, Liu et al. [49] examined the competitive association and uncertainty transfer between the oil market and the U.S. stock market. Their findings revealed a solid time-varying positive association between oil and stock implied volatility returns. During the financial crisis, there is a significant reversible inferred volatility spillover among oil and stock markets, which increases the association between the two.

Studies also found that individual stock prices tend to fall rather than going up when the market faces extreme conditions [50]. Li \& Peng [51] proved the negative association between the uncertainty index of economic policy and co-movements in stock markets.

Within a time-frequency system, researchers established a connection between the rapid spread of COVID-19, oil price instability spike, the stock market, geopolitical crisis, and economic policy instability in the United States. The COVID-19 has a much more significant impact on global instability than economic insecurity in the United States. The COVID-19 vulnerability is regarded differently in the short and long term, and it can be viewed as a financial crisis at first. According to Ashraf, [52], increasing COVID-19 confirmed cases has a negative effect on stock market responses. While the number of reported cases grew, so did stock market returns. Furthermore, the number of confirmed cases triggered a more positive reaction from financial markets than the number of deaths. Overall, financial markets reacted rapidly to the COVID-19 pandemic, though the timing of this reaction varied based on the level of the epidemic.

All studies mentioned above are frequently examined based on monthly or annual data, and studies overlook the daily changes of the stock market on account of limited data. Nevertheless, it is observed that all economic factors significantly affect stock returns, either short or long term.

\section{Hypotheses}

Hypotheses supporting the study are as follows:

H1: The share prices are affected by events/news.

H0: The Share prices are not affected by events/news. 


\section{Data and Methodology}

It analyses the impacts of policies announcement and news/events related to daily movements in the KSE-100 Index. Stock data and news sorting (causes/reasons) are collected from the daily newspaper "The News" 2

The data included in this study were from January 2010 to June 2019 and 2,084 observations in total. Changes in stock markets and daily events have been reported in the newspaper. We sorted data into eight-group categories (namely Economic, Financial, Foreign Relations, Global, Institutions, Investments in Blue Chips, Political, and Profit Taking) to structure transparent methodology and interpretation of outcomes. Afterward, we made sub-groups of these categories to inspect the extent of individual data series. We observed whether each factor had a positive or negative or no impact on the stock market. The figure below shows how the stock market reacts to news/events and how the stock market goes up and down.

Figure 1

KSE-100 index overall week movements

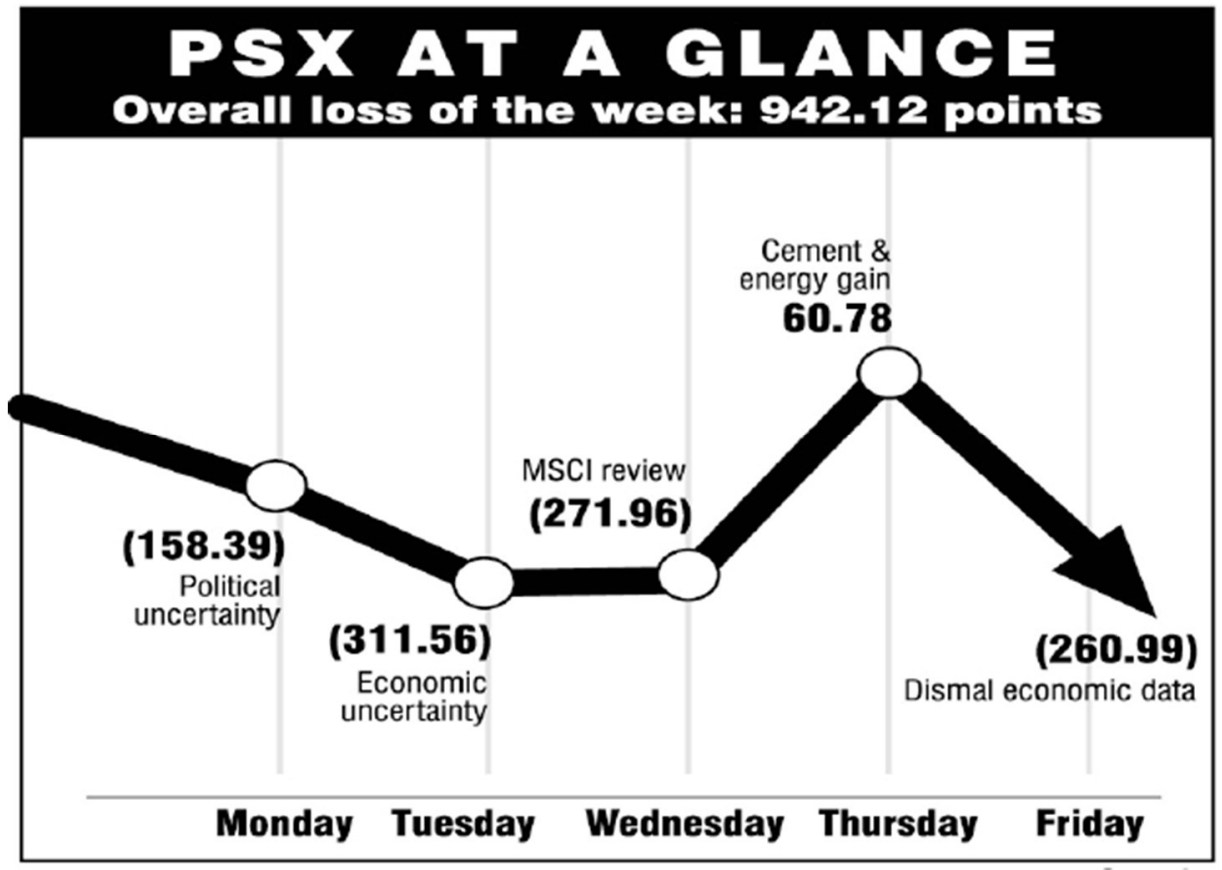

Figure 1. The figure above shows how the stock market reacts to news/events, and the stock market goes up and down. https://e.thenews.com.pk/5-13-2018/page16.asp

\footnotetext{
2 "The News" is a daily newspaper. In Sunday Edition, the news research team reports the whole week stock exchange changes. https://e.thenews.com.pk/5-13-2018/page16.asp
} 
Under the Political category, different sub-groups such as situations such as Political turmoil, Supreme Court orders, Former Prime Minister and President arrested in cases of corruption, 18th amendment, Blasts in different cities of the country, the Law and order situation in the country, National Reconciliation Ordinance (NRO) were recorded, Various news/events were observed under the Economic variable, such as a change in oil, gas, and electric power prices, monetary policy, uncertainty on CGS rate, federal budget, CGT rates, corporate sector policy rates, inflation, fiscal deficit, discount rate, energy shortfall, interest rate, VAT implementation, etc. were monitored.

Under the Financial variable, all diverse sub-groups were included, such as foreign dealings (buying and selling), inflows, joint funds, Mobile Telephony Services (MTS), duties, rollover, etc. Under the Global variable, global news and incidents which caused positively or negatively to the stock exchange of Pakistan were sub-grouped. ADB reports about country performance, the IMF bailout plan, changing situations in world markets and Asian markets, foreign interest, change in international oil and gas prices, and regional uncertainty.

Under Institution's variable, some of the events related to institutions (e.g., State Bank of Pakistan (SBP), Oil and Gas Regulatory Authority (OGRA), Securities and Exchange Commission of Pakistan (SECP), Oil and Gas Development Company Limited, National Bank of Pakistan (NBP), Pakistan Petroleum Limited (PPL), Speculative Buying, Cement Industry, Future settlement, Institutional support, Market Consolidating, etc.) which affected KSE positively and negatively. Under the Profit-Taking variable, Profit Taking, Selling pressure in the stock market, earnings in shares, sale of shares in the stock market were mainly observed.

In the Investment in Blue chips variable, the investments made in blue chips were included. Under the Foreign Relations variable, news and incidents related to foreign relations with other countries that positively or negatively impacted KSE were examined. That news was such as NATO and Pakistan, relations with the U.S., relations with the U.K., and border situations between Pakistan and India. Changes of KSE-100 index in the past 8-year period are shown in Figure 2 
Figure 2

\section{KSE Index Change}

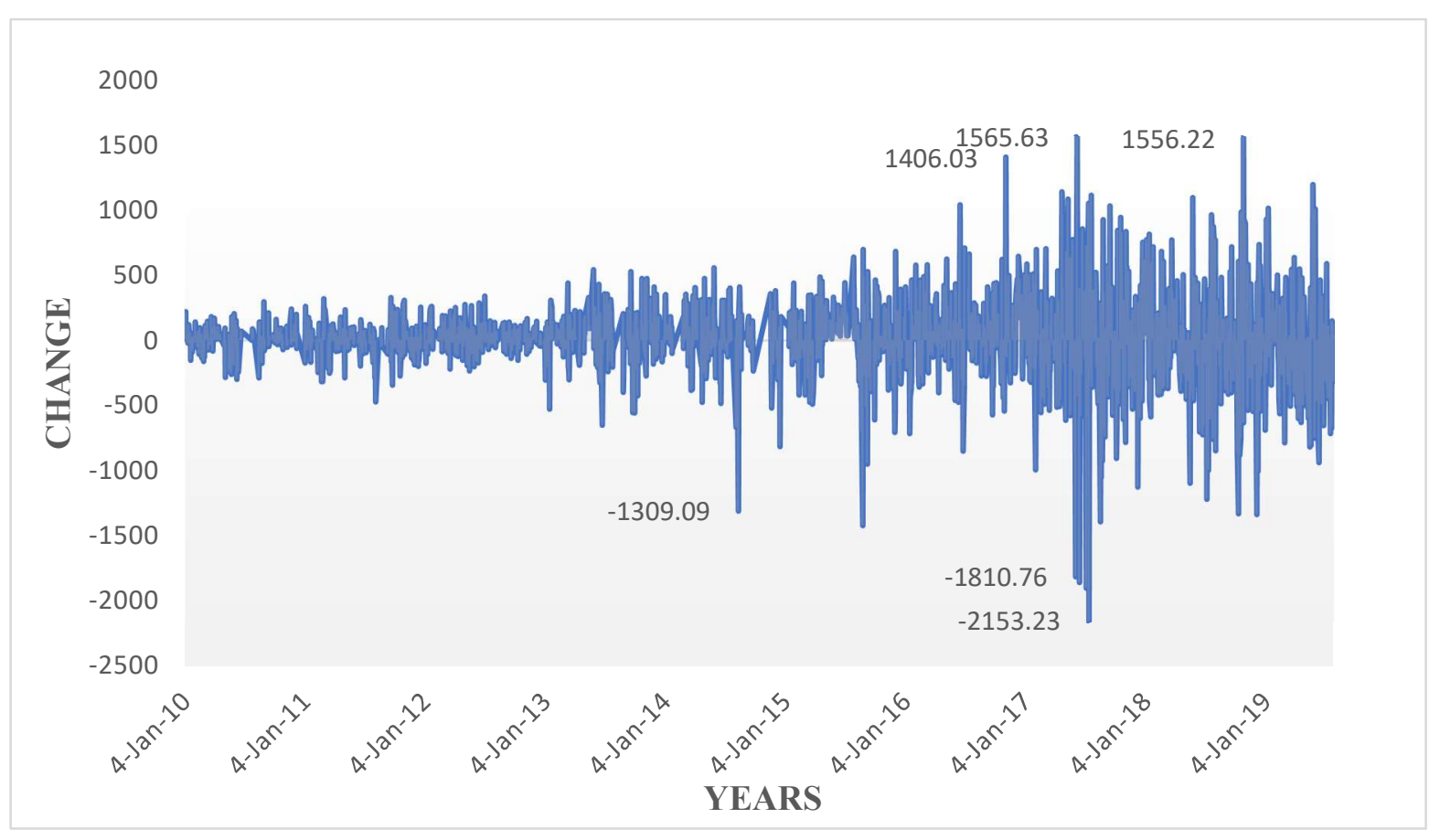

Figure 2. The overall changes in the KSE-100 index in the past 10-year period are shown in Figure 2

Figure 3

\section{KSE 100 Index Model}

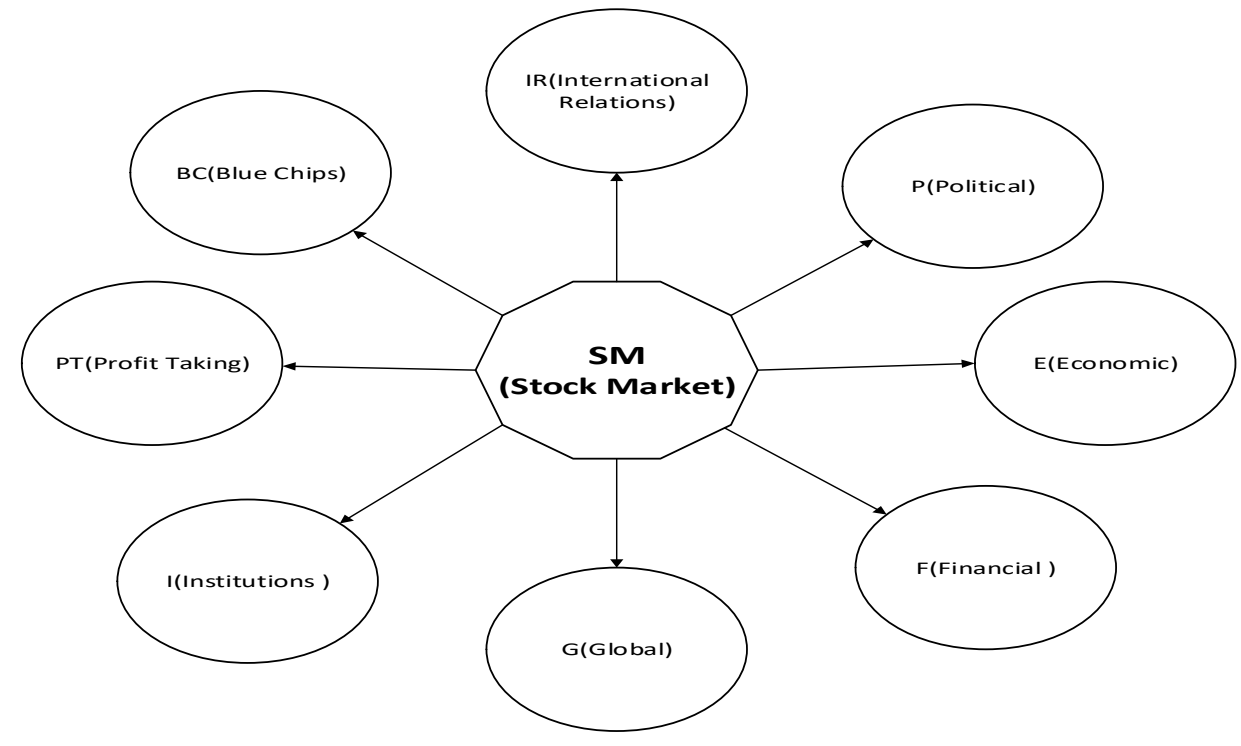

Figure 3. This figure illustrates the conceptual framework of this study. 


\subsection{OLS Regression}

In order to examine the impact of events/ news on the KSE 100 Index, two regression models were used on the dependent variable and eight independent variables associated with the news. This first regression model represents both the first and fifth lags, while the second model emphasizes the first lag.

\subsubsection{Model One}

Using model one with first and fifth lag. The regression model is constructed as follows:

$$
\begin{aligned}
\Delta \mathrm{KSE}_{\mathrm{t}}=\alpha_{0}+ & \alpha_{1} \Delta \mathrm{KSE}_{\mathrm{t}-1}+\alpha_{2} \Delta \mathrm{KSE}_{\mathrm{t}-5}+\beta_{1} \text { Political }+\beta_{2} \text { Economic }+\beta_{3} \text { Financial } \\
& +\beta_{4} \text { Global }+\beta_{5} \text { Instituitions }+\beta_{6} \text { Profit Taking }+\beta_{7} \text { Investment in Blue Chips } \\
& +\beta_{8} \text { Foreign Relations }+\varepsilon_{\mathrm{t}}
\end{aligned}
$$

Where,

$\alpha 0=$ the value of the stock market in the absence of " Financial, Economic, Foreign relationships Global, Political, Investment in blue chips Profit taking, and Institutions."

$\mathrm{t}-1=$ Lagged dependent variable, which is day-to-day trading

$\mathrm{t}-5=$ fifth lagged term of the dependent variables that stock market also responds to the weekly effect of stock market

\subsubsection{Model 2}

The fifth lag was omitted in this regression model two since it was found to be insignificant. Hence, the following model is constructed.

$$
\begin{aligned}
\Delta \mathrm{KSE}_{\mathrm{t}}=\alpha_{0}+ & \alpha_{1} \Delta \mathrm{KSE}_{\mathrm{t}-1}+\beta_{1} \text { Political }+\beta_{2} \text { Economic }+\beta_{3} \text { Financial }+\beta_{4} \text { Global } \\
& +\beta_{5} \text { Instituitions }+\beta_{6} \text { Profit Taking }+\beta_{7} \text { Investment in Blue Chips } \\
& +\beta_{8} \text { Foreign Relations }+\varepsilon_{\mathrm{t}}
\end{aligned}
$$

\subsubsection{ARCH and GARCH Models}

To evaluate the efficacy of risk premium, we use the log (variance) model along with MA (Moving Average), AR (Autoregressive), ARCH (Autoregressive Conditional Heteroscedasticity), and GARCH (Generalized Autoregressive Conditional Heteroscedasticity). A correlogram approach is used to identify ARiMA and ARCH/GARCH terms. Since AR (Autoregressive) term(s) were included, the lagged dependent variables were impracticable; they were used in the preceding regression models.

A time series model can be classified into three types: The ARMA (Autoregressive Moving Average) model, the ARCH (Autoregressive Conditional Heteroscedasticity) model, and the 
GARCH (Generalized Autoregressive Conditional Heteroscedasticity) model. In 1976, ARIMA(m, $\mathrm{D}, \mathrm{n})$ models were developed by Box and Jenkins [53], whereby $m$ is the number of autocorrelation terms, $\mathrm{D}$ the number of differentiating terms, and $\mathrm{n}$ the number of moving average periods. For the ARIMA model, the letter "I" is indicated when the time series is stationary. If the series were stationary, we can divide models into AR (Autoregressive), MA (Moving Average), and mixed AR/MA.

The autoregressive model $\mathrm{AR}(\mathrm{m})$ of order $\mathrm{m}$ is represented as

$$
\mathrm{Y}_{\mathrm{t}}=\mu+\emptyset_{1} \mathrm{~T}_{\mathrm{t}-1}+\emptyset_{2} \mathrm{Y}_{\mathrm{t}-2}+\cdots+\emptyset_{\mathrm{m}} \mathrm{Y}_{\mathrm{t}-\mathrm{m}}+\mathrm{u}_{\mathrm{t}}
$$

Here is how you can express MA(n) as a moving average of order $n$.

$$
Y_{t}=\mu+u_{t}+\theta_{1} u_{t-1}+\theta_{2} u_{t-2}+\cdots+\theta_{n} u_{t-n}
$$

Where $u_{t}(t=1 \ldots)$ is a white noise disturbance term with $E\left(u_{t}\right)=0$ and $\operatorname{var}\left(u_{t}\right)=\sigma^{2}$

$\mathrm{AR}(\mathrm{m})$ Autoregressive model and MA(n) Moving Average model together formed the $\operatorname{ARMA}(m, n)$ Autoregressive Moving Average model, which expressed as

$\mathrm{Y}_{\mathrm{t}}=\mu+\emptyset_{1} \mathrm{~T}_{\mathrm{t}-1}+\emptyset_{2} \mathrm{Y}_{\mathrm{t}-2}+\cdots+\emptyset_{\mathrm{m}} \mathrm{Y}_{\mathrm{t}-\mathrm{m}}+\theta_{1} \mathrm{u}_{\mathrm{t}-1}+\theta_{2} \mathrm{u}_{\mathrm{t}-2}+\cdots+\theta_{\mathrm{n}} \mathrm{u}_{\mathrm{t}-\mathrm{n}}+\mathrm{u}_{\mathrm{t}}$

the notation in sigma

$$
Y_{t}=C+\sum_{i=1}^{m} \emptyset_{i} Y_{t-i}+\sum_{j=1}^{n} \theta_{j} \varepsilon_{t-j}
$$

Where $Y_{t}$ denotes the daily KSE stock index prices, $\emptyset_{i}$ are the constraint of the AR (Autoregressive) component of order $\mathrm{m}, \theta_{\mathrm{j}}$ are the constraint of the MA (Moving Average) components of order $\mathrm{n}$ and $\mathrm{C}$ is the constant term, respectively, and $\varepsilon_{t}$ is the error term at a specific time $t$. The $\mathrm{m}$ and $\mathrm{n}$ integers are not negative.

The ARCH model and the GARCH model are the most commonly used time-variating volatility models among researchers. The ARCH model was developed by [54] to forecast the conditional variance of a return sequence.

$$
\begin{aligned}
& Y_{t}=C+\varepsilon_{t} \\
& \varepsilon_{t}=\sigma_{t} Z_{t}
\end{aligned}
$$


Where $\varepsilon_{t}$ is residual, $Z_{t}$ is the consistent residual with autonomously and identically distributed with mean equivalent to zero and variance of one, $\mathrm{C}$ is the constant, $Y_{t}$ is an observed series, and $\sigma_{t}$ is the square root of the conditional variance. According to Engle [54], the ARCH(q) model with the first q past squared novelties can be expressed as follows

$$
\sigma_{t}^{2}=\eta+\sum_{j=1}^{q} \alpha_{j} \varepsilon_{t-j}^{2}
$$

To certify the conditional variance, $\sigma_{t}^{2}$ must be rational number, as $\eta>0$ and $\alpha_{j}>0(j=1, \ldots, q)$. Despite its simple design and prevalence, the ARCH model has certain shortcomings. Several parameters need to be estimated in order to model volatility using ARCH. The difficulty to estimate parameters may result from this.

Based on the ARCH model, the GARCH model was established by Bollerslev [55] after four years. In contrast to the ARCH model, the GARCH model uses fewer parameters [56]. The GARCH model consists of two equations: the mean equation $Y_{t}$ in Eq. (4) and the variance equation $\sigma_{t}^{2}$ in Eq. (8). The GARCH (p, q) can be expressed in the general form as follows:

$$
\sigma_{t}^{2}=\eta+\sum_{i=1}^{p} \beta_{i} \sigma_{t-1}^{2}+\sum_{j=1}^{q} \alpha_{j} \varepsilon_{t-j}^{2}
$$

The long-term volatility of $\mathrm{n}$ is given by the conditions that $\mathrm{\eta}>0$, and $\beta_{i} \geq 0 ; i=1, \ldots$, whereas $p$ and $\alpha_{j} \geq 0 ; j=1, \ldots, q$. The GARCH model is covariance s stationary if $\beta_{i}+\alpha_{j}<1$.

\section{Findings}

We found that there were large numbers of both positive and negative changes in the past ten years. The standard deviation was 307.17, while the average was (+13.44) (shown in Table 2). As the highest decline was over the highest rise of the index, a panic attack was more than group actions in daily transactions. Our findings agreed with Hussain, Zaman, \& Ahmad [26].

Even though news of economic, financial, and institutional impact had a more significant proportion, as shown in Figure 3, institutional news was one of the vital causes for movements in KSE. According to our findings, financial change was 19 percent, the share of economic change was 18 percent, both political and Institution stood at 17 percent, profit-taking was 13 percent, and global change was 11 percent for the last ten years. We also found that foreign relations and 
investment in Blue Chips had a minor impact among all causes relating to changes in the stock market index.

On average, news on the economy gave positive outcomes, whereas both political and financial news adversely impacted a stock market index. Political News had a more substantial impact than economic and financial news. Institutional News also positively impacted the stock market index on average, even if the extreme decline was near 1,000 points. Global News such as oil prices could ferociously affect the stock market as the highest rise and fall were observed caused by global news. It had a negative impact on the stock market. Only when we excluded outliers can we have a realistic picture of global news. Profit-taking had an offset impact on the stock market. Even so, negative numbers denoted that it softened the overall stock market. Investments in Blue Chips had relatively less but significant influence on the stock exchange. We observed both positive and negative associations of foreign relations. Mostly, news of foreign relations had a positive impact on the KSE index.

\section{Figure 4}

KSE 100 Index Factors impact

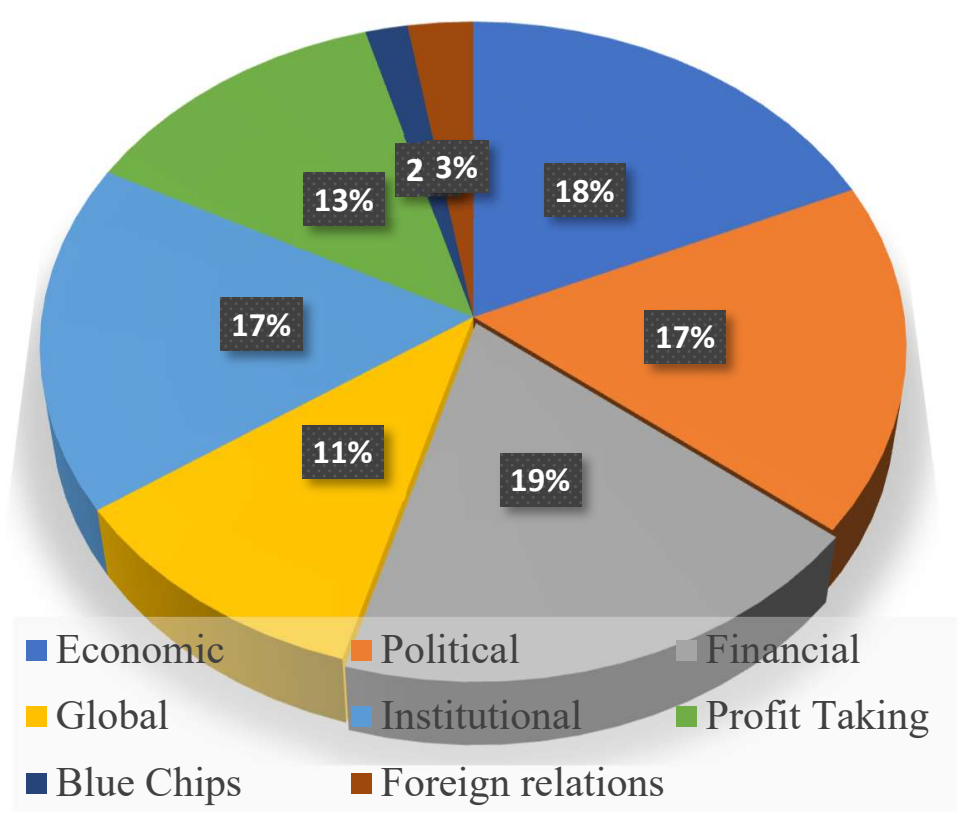

Figure 4.We illustrate how the stock market and eight variables influence it in this figure. 
Figure 5

Graph for primary reasons recorded

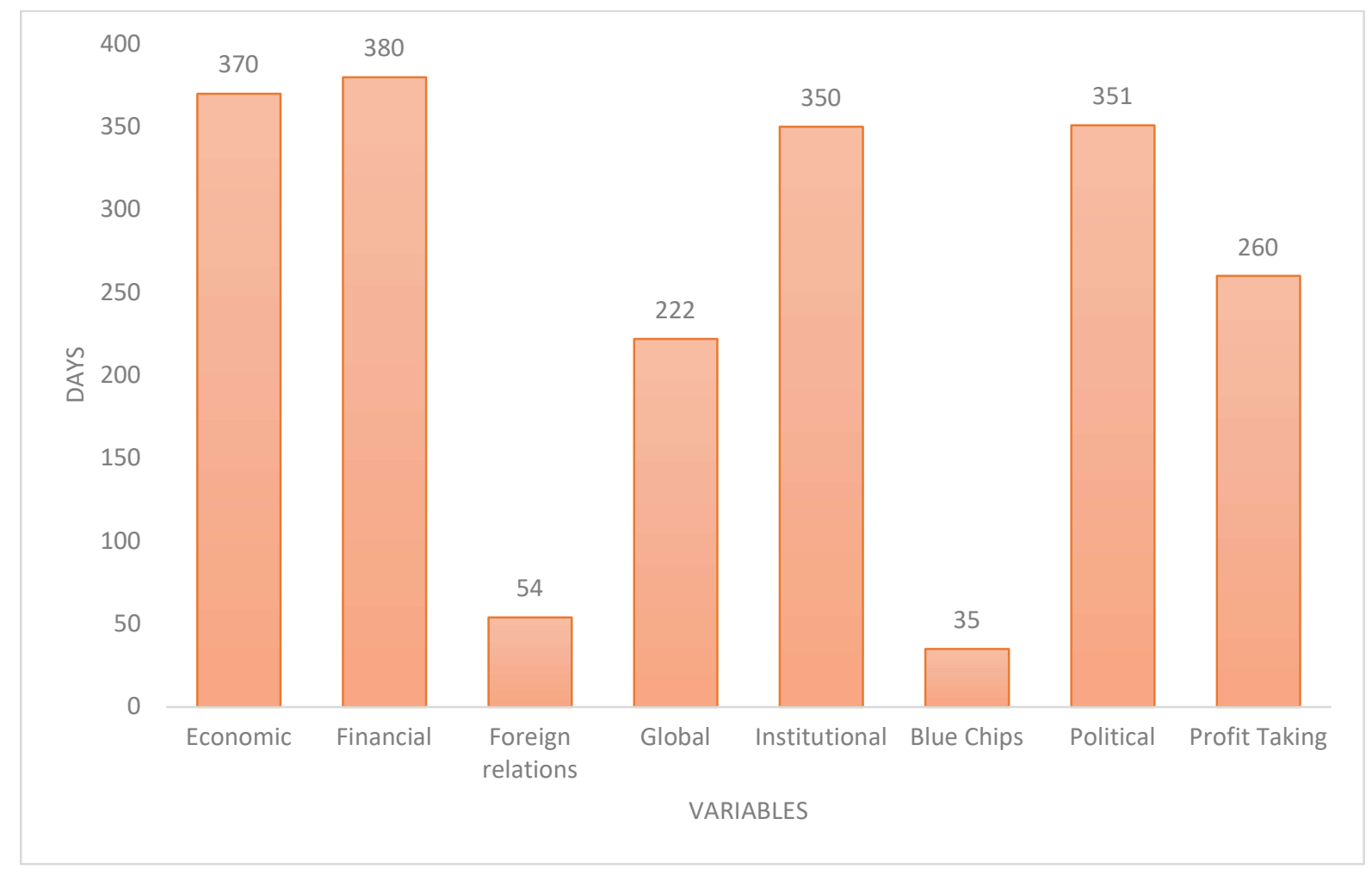

Figure 5. In this figure, we illustrate the number of assurance for every variable in the last ten years.

Table 2

Mean

\begin{tabular}{lcccc}
\hline Variables & Mean & Std. Deviation & Minimum & Maximum \\
\hline Economic & 24.62 & 280.69 & -992.00 & 1195.00 \\
Financial & -4.41 & 304.40 & -1811.00 & 1096.00 \\
Foreign relations & 25.56 & 195.94 & -644.00 & 387.00 \\
Global & -29.07 & 314.00 & -1855.00 & 1140.00 \\
Institutional & 115.02 & 277.58 & -1002.00 & 1566.00
\end{tabular}




\begin{tabular}{lcccc} 
Blue Chips & 79.66 & 239.63 & -702.00 & 533.00 \\
Political & -27.48 & 372.01 & -2153.00 & 1406.00 \\
Profit Taking & -33.12 & 277.15 & -844.00 & 1556.00 \\
\hline Total & $\mathbf{1 3 . 4 4}$ & $\mathbf{3 0 7 . 1 7}$ & $\mathbf{- 2 1 5 3 . 0 0}$ & $\mathbf{1 5 6 6 . 0 0}^{\mathbf{3}}$ \\
\hline All the key categories which cause all sorts of fluctuations in stock markets are reported as in Table \\
3:
\end{tabular}

Table 3

Results of key categories

\begin{tabular}{|l|c|c|c|c|c|}
\hline No. & News Categories & $\begin{array}{c}\text { Impact on } \\
\text { KSE index }\end{array}$ & $\begin{array}{c}\text { Average change in KSE } \\
\text { index in 8 years }\end{array}$ & $\begin{array}{c}\text { Highest } \\
\text { value }\end{array}$ & $\begin{array}{c}\text { Lowest } \\
\text { value }\end{array}$ \\
\hline 1 & Economic & Positive & 24.62 & 1195 & -992 \\
\hline 2 & Financial & Negative & -4.41 & 1096 & -1811 \\
\hline 3 & Foreign relations & Positive & 25.56 & 387 & -644 \\
\hline 5 & Global & Negative & -29.07 & 1140 & -1855 \\
\hline 6 & Institutional & Positive & 115.02 & 1566 & -1002 \\
\hline 7 & Political & Negative & -27.48 & 533 & -702 \\
\hline 8 & Profit Taking & Negative & -33.12 & 1406 & -2153 \\
\hline
\end{tabular}

Parameters were assessed using the ordinary least square and ARCH/GARCH model reported in Tables 4, 5, and 6 .

Table 4

Model-1Regression

$\begin{array}{lllll}\text { Variable } & \text { Coefficient } & \text { Std. Error } & \text { t-Statistic } & \text { Prob. }\end{array}$

\footnotetext{
${ }^{3}$ An Eight-factor mean table showing the mean, Std Deviation, Minimum and Maximum

${ }^{4}$ A comprehensive list of all the Eight key news/events, and the positive and negative impact they have on the markets, can be found in Table 3:
} 


\begin{tabular}{|c|c|c|c|c|}
\hline $\bar{C}$ & -70.28 & 39.00 & -1.80 & 0.072 \\
\hline KSE(-1) & 0.17 & 0.02 & 7.83 & 0.000 \\
\hline KSE(-5) & 0.04 & 0.02 & 2.08 & 0.038 \\
\hline POLITICAL & 40.76 & 42.15 & 0.97 & 0.334 \\
\hline ECONOMIC & 92.69 & 42.01 & 2.21 & 0.028 \\
\hline FINANCIAL & 64.86 & 41.92 & 1.55 & 0.122 \\
\hline INSTITUTIONS & 181.04 & 42.18 & 4.29 & 0.000 \\
\hline GLOBAL & 51.39 & 43.89 & 1.17 & 0.242 \\
\hline PROFIT_TAKING & 24.46 & 43.27 & 0.57 & 0.572 \\
\hline BLUE_CHIPS & 138.53 & 64.55 & 2.15 & 0.032 \\
\hline FOREIGN_RELATIONS & 97.96 & 56.41 & 1.74 & 0.083 \\
\hline R-squared & 0.06 & Mean dependent var & & 11.05 \\
\hline Adjusted R-squared & 0.06 & S.D. dependent var & & 308.19 \\
\hline S.E. of regression & 299.55 & Akaike info criterion & & 14.25 \\
\hline Sum squared resid & 185000000 & Schwarz criterion & & 14.28 \\
\hline Log likelihood & -14763.89 & Hannan-Quinn criter. & & 14.26 \\
\hline F-statistic & 13.13 & Durbin-Watson stat & & 1.99 \\
\hline Prob(F-statistic) & 0.000 & & & 5 \\
\hline
\end{tabular}

\footnotetext{
${ }^{5} \mathrm{~A}$ Regression Model of the parameters was constructed using first and fifth lagged data using ordinary least squares (OLS) in Table 4.
} 
Table 5

Model-2 Regression

\begin{tabular}{|c|c|c|c|c|}
\hline Variable & Coefficient & Std. Error & t-Statistic & Prob. \\
\hline $\bar{C}$ & -71.78 & 30.16 & -2.38 & 0.017 \\
\hline $\mathrm{KSE}(-1)$ & 0.07 & 0.02 & 4.30 & 0.000 \\
\hline POLITICAL (-) & -187.87 & 34.71 & -5.41 & 0.000 \\
\hline POLITICAL $(+)$ & 292.49 & 35.07 & 8.34 & 0.000 \\
\hline ECONOMIC (-) & -114.40 & 35.12 & -3.26 & 0.001 \\
\hline ECONOMIC (+) & 268.52 & 34.29 & 7.83 & 0.000 \\
\hline FINANCIAL (-) & -138.36 & 34.64 & -3.99 & 0.000 \\
\hline FINANCIAL $(+)$ & 262.57 & 34.44 & 7.62 & 0.000 \\
\hline INSTITUTIONS (-) & -144.86 & 41.23 & -3.51 & 0.001 \\
\hline INSTITUTIONS (+) & 265.56 & 33.19 & 8.00 & 0.000 \\
\hline GLOBAL (-) & -167.28 & 37.85 & -4.42 & 0.000 \\
\hline GLOBAL $(+)$ & 231.84 & 36.89 & 6.29 & 0.000 \\
\hline PROFIT TAKING (-) & -94.05 & 35.08 & -2.68 & 0.007 \\
\hline PROFIT TAKING (+) & 269.84 & 38.76 & 6.96 & 0.000 \\
\hline BLUE CHIPS (-) & -150.67 & 87.30 & -1.73 & 0.085 \\
\hline BLUE CHIPS $(+)$ & 236.66 & 53.83 & 4.40 & 0.000 \\
\hline FOREIGN RELATIONS (-) & -68.76 & 56.96 & -1.21 & 0.228 \\
\hline FOREIGN RELATIONS (+) & 222.13 & 51.40 & 4.32 & 0.000 \\
\hline R-squared & 0.44 & \multicolumn{2}{|l|}{ Mean dependent var } & 11.19 \\
\hline Adjusted R-squared & 0.43 & \multicolumn{2}{|l|}{ S.D. dependent var } & 307.93 \\
\hline S.E. of regression & 231.66 & \multicolumn{2}{|l|}{ Akaike info criterion } & 13.74 \\
\hline Sum squared resid & 111000000 & \multicolumn{2}{|l|}{ Schwarz criterion } & 13.79 \\
\hline Log likelihood & -14254.82 & \multicolumn{2}{|l|}{ Hannan-Quinn criter. } & 13.75 \\
\hline F-statistic & 94.68 & \multicolumn{2}{|l|}{ Durbin-Watson stat } & 2.01 \\
\hline Prob(F-statistic) & 0.000 & & & 6 \\
\hline
\end{tabular}

${ }^{6}$ we separately regressed positive and negative values while running a regression. By first lag and the fifth lag, we had assessed model 2. As we found the fifth lag was considered insignificant, we omitted it. 
Table 6

ARCH/GARCH Regression

\begin{tabular}{|c|c|c|c|c|}
\hline Variable & Coefficient & Std. Error & z-Statistic & Prob. \\
\hline LOG(GARCH) & 10.09 & 5.27 & 1.91 & 0.056 \\
\hline $\mathrm{C}$ & -127.76 & 55.69 & -2.29 & 0.022 \\
\hline POLITICAL (-) & -90.34 & 21.13 & -4.28 & 0.000 \\
\hline POLITICAL (+) & 169.25 & 22.33 & 7.58 & 0.000 \\
\hline ECONOMIC (-) & -85.92 & 21.63 & -3.97 & 0.000 \\
\hline ECONOMIC (+) & 144.81 & 22.40 & 6.46 & 0.000 \\
\hline FINANCIAL (-) & -86.36 & 21.19 & -4.08 & 0.000 \\
\hline FINANCIAL (+) & 173.59 & 21.58 & 8.04 & 0.000 \\
\hline INSTITUTIONS (-) & -84.33 & 25.96 & -3.25 & 0.001 \\
\hline INSTITUTIONS (+) & 160.06 & 21.06 & 7.60 & 0.000 \\
\hline GLOBAL (-) & -103.25 & 22.18 & -4.65 & 0.000 \\
\hline GLOBAL $(+)$ & 135.34 & 25.07 & 5.40 & 0.000 \\
\hline PROFIT TAKING (-) & -69.47 & 21.88 & -3.18 & 0.002 \\
\hline PROFIT TAKING $(+)$ & 136.99 & 27.83 & 4.92 & 0.000 \\
\hline BLUE CHIPS (-) & -54.11 & 53.49 & -1.01 & 0.312 \\
\hline BLUE CHIPS (+) & 129.95 & 44.33 & 2.93 & 0.003 \\
\hline FOREIGN RELATIONS (-) & -140.42 & 46.35 & -3.03 & 0.002 \\
\hline FOREIGN RELATIONS (+) & 151.61 & 31.85 & 4.76 & 0.000 \\
\hline $\operatorname{AR}(1)$ & 0.12 & 0.03 & 4.55 & 0.000 \\
\hline \multicolumn{5}{|c|}{ Variance Equation } \\
\hline $\mathrm{C}$ & 14478.83 & 1552.39 & 9.33 & 0.000 \\
\hline $\operatorname{RESID}(-1)^{\wedge} 2$ & 0.20 & 0.01 & 14.14 & 0.000 \\
\hline $\operatorname{RESID}(-2)^{\wedge} 2$ & 0.29 & 0.01 & 20.38 & 0.000 \\
\hline $\operatorname{RESID}(-3)^{\wedge} 2$ & 0.35 & 0.02 & 20.59 & 0.000 \\
\hline $\operatorname{RESID}(-4)^{\wedge} 2$ & 0.29 & 0.01 & 19.60 & 0.000 \\
\hline $\operatorname{RESID}(-5)^{\wedge} 2$ & 0.18 & 0.01 & 19.83 & 0.000 \\
\hline
\end{tabular}




\begin{tabular}{ccccc} 
GARCH(-1) & -0.77 & 0.00 & -187.52 & 0.000 \\
GARCH(-2) & -0.48 & 0.00 & -313.27 & 0.000 \\
GARCH(-3) & -0.25 & 0.02 & -15.85 & 0.000 \\
GARCH(-4) & 0.32 & 0.00 & 104.84 & 0.000 \\
GARCH(-5) & 0.70 & 0.01 & 61.34 & 0.000 \\
\hline R-squared & 0.36 & Mean dependent var & 11.19 \\
\hline Adjusted R-squared & 0.36 & S.D. dependent var & 307.93 \\
\hline S.E. of regression & 247.10 & Akaike info criterion & 13.29 \\
\hline Sum squared resid & 126000000 & Schwarz criterion & 13.38 \\
\hline Log likelihood & -13782.04 & Hannan-Quinn criter. & 13.32 \\
\hline Durbin-Watson stat & 2.01 & & 7 \\
\hline Discussion & & &
\end{tabular}

Excluding the first and fifth lag, we found that institution variable, economic and blue chips variable were significant though other variables were insignificant. We assumed that this was because of equalizing the values. Thus, we separately regressed positive and negative values while running a regression. By first lag and the fifth lag, we had assessed model 2. As we found the fifth lag was considered insignificant, we omitted it.

Coefficients were shown in Table 5. We found that all variables except foreign relations had resulted in $8 \%$ significance. The coefficient of Foreign relations was insignificant because of investors' reaction to save when prices went down in the stock market.

We found the negative impact of all other types of news except economic news on the stock market. We also noticed that the sudden changes in the stock market befell at the time of negative news. Conversely, changes are "a random walk." When there was positive news, investors were more alert in investing. From this, we can understand the risk-cautious nature of investors.

ARCH/GARCH estimation results are reported in Table 4. To evaluate the efficacy of risk premium, we use the log (variance) model along with MA (Moving Average), AR

\footnotetext{
${ }^{7}$ We used a correlogram to identify Arima and ARCH/GARCH terms. In contrast to Model 1 and Model 2, we found the more significant influence of political, financial, and economic news on positive fluctuations. ARCH and GARCH coefficients displayed strong influences of three sorts of news which signified non-linear inertia in stock upheaval.
} 
(Autoregressive), ARCH (Autoregressive Conditional Heteroscedasticity), and GARCH (Generalized Autoregressive Conditional Heteroscedasticity). A correlogram approach is used to identify ARiMA and ARCH/GARCH terms. Since AR (Autoregressive) term(s) were included, the lagged dependent variables were impracticable; they were used in the preceding regression models.

We used a correlogram to identify Arima and $\mathrm{ARCH} / \mathrm{GARCH}$ terms. As accounts receivable term(s) was included, lagged dependent variable was not used. We found a significant coefficient of risk premium, which agreed with $[57,58]$. We used five terms of ARCH and GARCH. Adding all five gave the good-fit model, albeit every coefficient was not significant. ARCH and GARCH approved non-linear inertia. Results were relatively the same as concerns of the level of significance. All variables were insignificant to negative variations in the stock market, while investment in Blue Chips was significant to positive fluctuations in the stock market. In contrast to Model 1 and Model 2, we found the more significant influence of political, financial, and economic news on positive fluctuations. ARCH and GARCH coefficients displayed strong influences of three sorts of news which signified non-linear inertia in stock upheaval.

\section{Conclusion}

Many factors can observe the swift nature of the stock market. Economic factors can explain monthly movements. On the other hand, daily changes are hard to anticipate, and it is only possible by the approach of news impact. We examined daily fluctuations in the stock market by news categories. Our findings proved that global and political news had a substantial effect on the stock market. So, individuals or Institutions may exploit global and political news to influence the stock market. Besides political, economic, and financial news, negative news will result in a hazardous stock exchange. Investments in Blue Chips were the result rather than the cause of fluctuations in the stock market. Investors also promptly respond to negative news.

\section{Limitations}

We provided a significant contribution to stock market studies. Several improvements have been developed as a result of the impact of the news. The news we collected were a daily basis. The nature of news was a short-term effect. From the aspect of news impact, we could explain the fluctuations of stock markets to some extent. However, there are some limitations in our study. 
The first limitation is that long-term decline in stock markets cannot be explained by news impact since the news has a short-term effect. The second limitation is that this study observed one country only. If future studies are based on cross-national analysis, it will provide a broader picture of the swift nature of stock markets.

\section{Recommendations}

Profit-taking and the KSE index had a negative association. For profit-taking, we used selling pressure, earning shares, and sale continues. Because of the negative association, the more hazard these factors will result, the more decline of the stock market will become. When investors sensed less vulnerability, they tended to invest in stock and would lead to ascending trend in the stock market.

This study verified that the stock market has insignificant relationships with investments in Blue chips and bilateral and multilateral relationships. These factors may be substantial in other markets. Consequently, our results of all sorts of news suggested to investors the future foretaste of performance in the stock market.

Stock prices will go high after economic and Institution features are positively improved so that investors can purchase the shares in that scenario. The more individuals invest in stocks, the higher the stock prices become. As a result, investors can get more benefits. When it is further hazardous of accumulative profit-taking, the prices in the stock market will decline further. Hereafter, investors can be well aware and pay attention to our proposed necessary signals while investing in the stock market.

Acknowledgments: The author would like to express his high appreciation to Dr. Sun Bai Qing, Associate Professor, Harbin Institute of Technology, China, for providing his valuable supervision during this research..

\section{References}

[1] A. Singh, "Financial liberalisation, stockmarkets and economic development*," (in en), The Economic Journal, vol. 107, no. 442, pp. 771-782, 1997/05// 1997, doi: 10.1111/j.1468-0297.1997.tb00042.x. 
[2] A. Demirguc-Kunt and R. Levine, "Stock market development and financial intermediaries: stylized facts," (in en), The World Bank Economic Review, vol. 10, no. 2, pp. 291-321, 1996/05/01/ 1996, doi: 10.1093/wber/10.2.291.

[3] E. F. Fama, "Efficient capital markets: a review of theory and empirical work," The Journal of Finance, vol. 25, no. 2, p. 383, 1970/05// 1970, doi: 10.2307/2325486.

[4] E. F. Fama, "Stock returns, real activity, inflation, and money," The American Economic Review, vol. 71, no. 4, pp. 545-565, 19811981.

[5] J. K. Kemboi and D. Tarus, "Macroeconomic Determinants of Stock Market Development in Emerging Markets: Evidence from Kenya," Research Journal of Finance and Accounting, vol. 3, pp. 57-68, 2012.

[6] M. Cherif and K. Gazdar, "Institutional and macroeconomic determinants of stock market development in mena region: new results from a panel data analysis," (in en-US), International Journal of Banking and Finance, vol. 7, no. 1, pp. 139-159, 2010/03/10/ 2010.

[7] E. F. Fama, "The behavior of stock-market prices," (in en), The Journal of Business, vol. 38, no. 1 , p. 34, 1965/01// 1965, doi: 10.1086/294743.

[8] J. Press and L. Fang, "Media Coverage and the Cross-Section of Stock Returns," The Journal of Finance, vol. 64, pp. 2023-2052, 2009.

[9] C. Dougal, J. Engelberg, D. Garc'ıa, and C. A. Parsons, "Journalists and the Stock Market," The Review of Financial Studies, vol. 25, pp. 639-679, 2011.

[10] P. C. Tetlock, "Giving Content to Investor Sentiment:The Role of Media in the Stock Market," The Journal of Finance, 2007.

[11] M. L. Mitchell and J. H. Mulherin, "The Impact of Public Information on the Stock Market," The Journal of Finance, 1944.

[12] S. Dupernex, "Why might share prices follow a random walk?," Student Economic Review, pp. 167-179, 2007.

[13] F. N. Shubiri, "Analysis the Determinants of Market Stock Price Movements: An Empirical Study of Jordanian Commercial Banks," International Journal of Business and Management, pp. 137-147, 2010.

[14] M. I. J. Attari and L. Safdar, "The Relationship between Macroeconomic Volatility and the Stock Market Volatility: Empirical Evidence from Pakistan," Pakistan Journal of Commerce and Social Sciences, 2013.

[15] M. Nishat and R. Shaheen, "Macroeconomic Factors and Pakistani Equity Market," The Pakistan Development Review, pp. 619-637, 2004.

[16] A. Hussain, G. Zaman, and Q. B. Baloch, "The Causal Relationship of Interest Rate and Stock Prices: Empirical Evidence from Pakistan Markets," City University Research Journal, 2014.

[17] Z. Tonghui, Y. Ying, and W. Xi, "Is microblogging data reflected in stock market volatility? Evidence from Sina Weibo," Finance Research Letters, vol. 32, 2020.

[18] R. Zhao, "Inferring private information from online news and searches: Correlation and prediction in Chinese stock market," Physica A, 2019.

[19] S. M. Hussain and W. B. Omrane, "The effect of US macroeconomic news announcements on the Canadian stock market: Evidence using high-frequency data," Finance Research Letters, 2020. 
[20] G. G.-R. Wu, T. C.-T. Hou, and J.-L. Lin, "Can economic news predict Taiwan stock market returns?," Asia Pacific Management Review, 2018.

[21] M. S. Nazir, M. M. Nawaz, W. Anwar, and F. Ahmed, "Determinants of Stock Price Volatility in Karachi Stock Exchange: The Mediating Role of Corporate Dividend Policy," International Research Journal of Finance and Economics, 2010.

[22] S. Erdogan, A. Gedikli, and E. İ. Çevik, "Volatility Spillover Effects Between Islamic Stock Markets And Exchange Rates: Evidence From Three Emerging Countries," Borsa istanbul Review, 2020.

[23] Y. Li, X. Zhuang, J. Wang, and W. Zhang, "Analysis of the impact of Sino-US trade friction on China's stock market based on complex networks," North American Journal of Economics and Finance, 2020.

[24] X. Su, "Dynamic behaviors and contributing factors of volatility spillovers across G7 stock markets," North American Journal of Economics and Finance, no. 53, 2020.

[25] Z. Dai, H. Zhou, F. Wen, and S. He, "Efficient predictability of stock return volatility: The role of stock market implied volatility," North American Journal of Economics and Finance, 2020.

[26] M. Hussain, B. Zaman, and N. Ahmad, "Relationship between Stock Market Volatility and Macro Economic Variables: Evidence from Pakistan," Pakistan Business Review, pp. 723743, 2015.

[27] M. Tule, M. Dogo, and G. Uzonwanne, "Volatility of stock market returns and the naira exchange rate," Global Finance Journal, pp. 97-105, 2018.

[28] Y. Shen, "International risk transmission of stock market movements," Economic Modelling, 2018.

[29] F. Hussain and T. Mahmood, "The Stock Market and the Economy in Pakistan," The Pakistan Development Review, pp. 107-114, 2001.

[30] A. Humpe and P. Macmillan, "Can macroeconomic variables explain long-term stock market movements? A comparison of the US and Japan," Applied Financial Economics, pp. 111-119, 2009.

[31] M. Saeedian, T. Jamali, M. Z. Kamali, H. Bayani, T. Yasseri, and G. R. Jafari, "Emergence of world-stock-market network," Physica A, 2019.

[32] Y. Zhang, Q. Jia, and C. Chen, "Risk attitude, Financial Literacy and Household Consumption: Evidence from Stock Market Crash in China," Economic Modelling, 2020.

[33] M. U. Javaid, "Determinants of Equity Prices in the Stock Market," A Research Journal of Commerce, Economics and Social Sciences, pp. 98-114, 2010.

[34] M. Nisa and M. Nishat, "The Determinants of Stock Prices in Pakistan," Asian Economic and Financial Review, pp. 276-291, 2012.

[35] M. S. Nazir, M. M. Nawaz, and U. J. Gilani, "Relationship between economic growth and stock market development," African Journal of Business Management, vol. Vol. 4(16), pp. 3473-3479, 2010.

[36] D. Aurangzeb, "Factors Affecting Performance of Stock Market: Evidence from South Asian Countries," International Journal of Academic Research in Business and Social Sciences, vol. Vol. 2, No. 9, pp. 1-15, 2012. 
[37] N. Sohail and Z. Hussain, "Long-run and Short-run Relationship between Macroeconomic Variables and Stock Prices in Pakistan: The Case of Lahore Stock Exchange," Pakistan Economic and Social Review, pp. 183-198, 2009.

[38] A. Chatrath, S. Ramchander, and S. Frank, "Stock prices, inflation and output: Evidence from India," Journal of Asian Economics, pp. 237-245, 1996.

[39] E. F. Fama and K. R. French, "Size and Book - to - Market Factors in Earnings and Returns," The Journal of Finance, pp. 1-25, March 1995.

[40] A. Haque and S. Sarwar, "Macro-Determinants of Stock Return in Pakistan," Middle-East Journal of Scientific Research, pp. 504-510, 2012.

[41] Z. Alam and K. Rashid, "Time Series Analysis of the Relationship between Macroeconomic Factors and the Stock Market Returns in Pakistan," Journal of Yasar University, 2014.

[42] K. Wu, J. Zhu, M. Xu, and L. Yang, "Can crude oil drive the co-movement in the international stock market? Evidence from partial wavelet coherence analysis," North American Journal of Economics and Finance, no. 53, 2020.

[43] S. Singhal, S. Choudhary, and P. C. Biswal, "Return and volatility linkages among International crude oil price, gold price, exchange rate and stock markets: Evidence from Mexico," Resources Policy, pp. 255-261, 2019.

[44] A. Qayyum and S. Anwar, "Impact of Monetary Policy on the Volatility of Stock Market in Pakistan," Pakistan Development Economics, 2011.

[45] B. Lin and T. Su, "The linkages between oil market uncertainty and Islamic stock markets: Evidence from quantile-on-quantile approach," Energy Economics, 2020.

[46] M. A. Cheema and F. Scrimgeour, "Oil prices and stock market anomalies," Energy Economics, no. 83, pp. 578-587, 2019.

[47] J. O. Ferreiro, "Disentangling the role of the exchange rate in oil-related scenarios for the European stock market," Energy Economics, 2018.

[48] N. K. Cevik, Cevik, Emrah I., and S. Dibooglu, "Oil Prices, Stock Market Returns and Volatility Spillovers: Evidence from Turkey," Journal of Policy Modeling, 2020.

[49] Z. Liu, H.-K. Tseng, J. S. Wu, and Z. Ding, "Implied volatility relationships between crude oil and the U.S. stock markets: Dynamic correlation and spillover effects," Resources Policy, vol. 66, 2020.

[50] Y. Liu and X. Yang, "Asymmetric Synchronicity in Extreme Stock Price Movements: Evidence from China's Stock Market," Information Technology and Quantitative Management (ITQM 2017), pp. 156-1161, 2017.

[51] X. M. Li and L. Peng, "US economic policy uncertainty and co-movements between Chinese and US stock markets," Economic Modelling, pp. 27-39, 2017.

[52] B. N. Ashraf, "Stock markets' reaction to COVID-19: cases or fatalities?," Research in International Business and Finance, 2020.

[53] G. E. P. Box and G. M. Jenkins, Time series analysis: forecasting and control, Rev. ed ed. (Holden-Day series in time series analysis and digital processing). San Francisco: HoldenDay, 1976, p. 575.

[54] R. F. Engle, "Autoregressive conditional heteroscedasticity with estimates of the variance of united kingdom inflation," Econometrica, vol. 50, no. 4, p. 987, 1982/07// 1982, doi: 10.2307/1912773. 
[55] T. Bollerslev, "Generalized autoregressive conditional heteroskedasticity," (in en), Journal of Econometrics, vol. 31, no. 3, pp. 307-327, 1986/04// 1986, doi: 10.1016/03044076(86)90063-1.

[56] S.-H. Poon and C. W. J. Granger, "Forecasting volatility in financial markets: a review," (in en), Journal of Economic Literature, vol. 41, no. 2, pp. 478-539, 2003/06// 2003, doi: 10.1257/jel.41.2.478.

[57] S. Z. Shirazi, "Risk, Return and Asymmetric Volatility at the Karachi Stock Exchange.," Quaid-i-Azam University, (MSc Thesis), Islamabad, 1999.

[58] E. Ahmad and B. U. Zaman, "Risk, Uncertainty and Return at Karachi Stock Exchange," The Lahore Journal of Economics, vol. 15, pp. 107-126, 2000. 